\title{
UMA ANÁLISE DO VALOR DO USO DA PAISAGEM DA VILA DE IGATU E DO PROJETO BREJO VERRUGA IGATU, BAHIA: MÉTODO DE VALORAÇÃO CUSTO DE VIAGEM
}

\author{
Delaa Rodrigues de Carvalho ${ }^{1}$
}

\begin{abstract}
RESUMO
Este trabalho está fundamentado nos pressupostos teóricos do método de avaliação ambiental, denominado "Custo de Viagem", utilizado para valorar o ativo patrimonial da Vila de Igatu e do Projeto Brejo Verruga, ambos, localizados no município de Andaraí-BA. A pesquisa in loco de avaliação monetária do uso direto para fins recreativos foi desenvolvida durante os meses de Outubro e Novembro/2016 (época de aulas e normalmente com chuvas), férias escolares e verão, até Fevereiro de 2017. A pesquisa incluiu ainda um estudo do perfil do visitante, abordando seus gastos e hábitos durante a permanência em Andaraí e seu entorno. Nos resultados conclusivos, evidencia-se que o uso e a apropriação dos espaços pelos indivíduos, representados por turistas, empresários do turismo (donos de hotéis e agências de turismo), relacionados ao patrimônio ambiental e sociocultural da Vila de Igatu e do Projeto Brejo Verruga têm uma lógica contrária à percepção e vivência, porém, favorável à materialização do espaço concebido. Ainda constatou-se que as políticas públicas de sítios de interesse ambiental abertos à visitação não são compatíveis com o valor econômico atribuído a estes, tornando-se necessário estimar os preços sociais dos benefícios/custos que reflitam adequadamente o sistema de preços dos recursos naturais.
\end{abstract}

Palavras-chave: Método Custos de Viagem (MCV). Patrimônio Natural. Valoração econômica.

\begin{abstract}
This work is based on the theoretical assumptions of the environmental valuation method, called "Travel Cost", used to value the asset assets of Vila de Igatu and Projeto Brejo Verruga, both located in the municipality of Andaraí-BA. The on-the-spot survey of monetary evaluation of the direct use for recreational purposes was developed during the months of October and November /2016 (class time and usually with rains), school vacations and summer until February 2017. The research also included a study of the Profile of the visitor, addressing their spending and habits during their stay in Andaraí and its surroundings. In the conclusive results, it is evident that the use and appropriation of spaces by ind ividuals, represented by tourists, tourism entrepreneurs (hotel owners and tourism agencies), related to the environmental and socio-cultural heritage of Vila de Igatu and Projeto Brejo Verruga, Have a logic contrary to perception and experience, but favorable to the materialization of the space conceived. It was also found that the public policies of sites of environmental interest open to visitation are not compatible with the economic value attributed to them, making it necessary to estimate the social prices of benefits / costs, which adequately reflect the system of prices of resources Natural.
\end{abstract}

Keywords: Travel Costs Method (MCV). Natural patrimony. Economic valuation.

\section{INTRODUÇÃO}

O presente artigo discute sobre a validade de aplicação do Método de avaliação ambiental, denominado "Custo Viagem", a partir da valoração da paisagem da Vila de Igatu e do Projeto Brejo Verruga, ambos, localizados no município de Andaraí, Bahia, centrada no sujeito (percepção geográfica).

Para tanto, utiliza-se de informações empíricas da pesquisa realizada durante os meses de Outubro e Novembro de 2016 (época de aulas e normalmente com chuvas), férias escolares e verão até

\footnotetext{
1 Professora da Universidade Estadual do Sudoeste da Bahia; Doutora em Geografia. Coordenadora do Programa de Extensāo: Indicadores Econômicos de Vitória da Conquista. E-mail: delrocar@hotmail.com
} 
Fevereiro de 2017.

Esse artigo tem como objetivo contribuir para o desenvolvimento do arcabouço teórico de pesquisa, necessário a investigação das hipóteses propostas na pesquisa intitulada, "O olhar geográfico sobre o patrimônio, turismo, identidades e representações territoriais em Igatu/Chapada Diamantina”, inscrita no programa de pesquisa da UESB, Campus de Vitória da Conquista.

A pesquisa propõe analisar o olhar geográfico do patrimônio histórico-cultural, do turismo, das identidades e representações territoriais em Igatu/Chapada Diamantina. Nesse sentido, destacam-se os múltiplos olhares dos diferentes agentes/atores Sociais, a partir do valor de uso da paisagem local.

Nesse propósito são discutidos os pressupostos valorativos do turismo, identidades e representações territoriais da Vila de Igatu e do Projeto Brejo Verruga. Em específico, esse projeto tem como objetivo analisar a refuncionalização do uso da gruta, a partir de um conjunto de modificações tanto materiais como simbólicas no espaço.

Dessa forma, os estudos que envolvem a valoração da paisagem se tornam cada vez mais importantes, pois podem apresentar soluções práticas de problemas de ocupação de territórios, planejamento ambiental e valoração de paisagem para conservação e proteção de áreas naturais.

A partir da valoração da paisagem podem-se obter informações que frisem a necessidade de conservar determinadas áreas do município e, ao mesmo tempo, um planejamento para ocupação de áreas que causem menos impacto ao ambiente. A pesquisa encontra-se inserida na área de interesse da Ciências Econômicas e Geografia, apoiada nos pressupostos da Teoria Neoclássica, que postula o princípio da soberania do consumidor, a partir das preferências individuais, por ser a de maior amplitude nas aplicações e usos dos ativos naturais pela atividade econômica.

A área de referência espacial de pesquisa compreende Vila de Igatu e o Projeto Brejo Verruga, ambos, localizados no município de Andaraí. Trata-se de uma região de grande importância turística. Nessa se encontra o mais belo cenário paisagístico montanhoso da Bahia, riqueza arquitetônica das cidades históricas, vegetação exótica, quedas d‘água, cavernas e ruínas de antigos povoados, que evocam o auge da mineração.

As escolhas do tema e área de pesquisa tiveram como objetivo valorar a percepção regional da população local acerca das representações em forma de bonecos feitos de argila, reconhecidos como vilão (os coronéis); herói (os garimpeiros); santo (Jesus crucificado) salvador (o médico que cuidava dos garimpeiros). Aliada as reflexões complementares - foi um meio de vida; um meio de morte; trouxe o progresso e retrocesso; trouxe a riqueza e a pobreza. Sempre dual, bom ou mau, alegre ou triste, salvador ou carrasco. Afinal, é um personagem vivo, presente em todos os momentos da vida dos habitantes da região, ricos e pobres, sentimentos impregnados na alma e no cotidiano das pessoas entrevistadas.

Face às questões que se apresentam com relação à temática fez-se o seguinte questionamento: Qual seria o valor médio e mediano, de uso, que a população estaria disposta a pagar pela 
conservação/preservação dos patrimônios naturais, localizados no Vila de Igatu e do Projeto Brejo Verruga?

Para auxiliar o desenvolvimento da investigação, acima mencionada, foi formulada a hipótese de que a técnica Método Custos de Viagem (MCV), constitui-se, num método de avaliação monetária, capaz de valorar o uso direto de locais, abertos à visitação pública em geral, a exemplo, dos parques nacionais brasileiros ou locais turísticos.

Esses recursos ambientais não têm preço no mercado convencional, mas as pessoas atribuemlhes valor em decorrência do lazer, da beleza do lugar, da estética ambiental. Esta técnica se baseia no princípio de que o tempo e o dinheiro gasto na viagem para um local específico para visitar uma área ambiental, indicam o valor deste bem. Uma curva de demanda é estimada através do incremento progressivo da taxa de admissão do local.

Nesse propósito, estimam-se "preços" para os ativos ambientais fornecendo-se subsídios técnicos necessários à justificativa de ações de investimentos em sítios naturais, principalmente, para definição de valores monetários, na forma de ingressos cobrados, que podem ser considerados a máxima disposição a pagar do usuário pelos serviços ambientais.

O presente artigo, além da introdução, está estruturado em quatro outras seções. $\mathrm{Na}$ seção 2 , são apresentados as Conceituais para Valoração da Paisagem: Vila de Igatu e Projeto Brejo Verruga-BA e o Método de Valoração Econômica Ambiental para mensuração do valor ambiental em atendimento à problemática e aos objetivos propostos na pesquisa.

$\mathrm{Na}$ seção 3, são apresentados, de forma resumida, os procedimentos metodológicos que foram realizados na pesquisa de campo para comprovação da hipótese da pesquisa.

$\mathrm{Na}$ seção 4, discutem-se os resultados sobre a aplicação do método custo viagem na área de estudo, abordando as principais características socioeconômicas dos entrevistados, o modelo estatístico e os resultados numéricos utilizados na estimação da disposição a pagar pela conservação/preservação da Vila de Igatu e do Projeto Brejo Verruga.

Por fim, na conclusão, retoma-se a assertiva definida na hipótese, buscando a sua validação respaldada nos resultados obtidos do trabalho empírico e referencial teórico metodológico utilizado.

\section{DISCUSSĀO}

\subsection{Categorias Conceituais para Valoração da Paisagem: Vila de Igatu e Projeto Brejo Verruga-} BA.

As representações da paisagem variam de indivíduo para indivíduo, pois a sua interação com o mundo é afetada por diversos fatores, primeiramente, por estar sujeita às particularidades das combinações de elementos físicos, biológicos e sociais do espaço e, também, por ser dependente das características fisiológicas individuais. 
Assim, as condições físicas dos órgãos sensoriais do sujeito, também, estão fortemente relacionadas às disposições da personalidade, sendo profundamente alteradas de acordo com motivação, cansaço, lembranças, expectativas e valores individuais.

Paisagem, segundo Santos (1988), é o resultado de tudo aquilo que vemos, o que a visão alcança, formada de volumes, cores, movimentos, odores e sons. De maneira sintética, a paisagem é formada por objetos materiais e imateriais. Segundo o autor, a dimensão da paisagem é a extensão da percepção, que chega aos sentidos. Daí a importância do sistema cognitivo, nessa apreensão, pelo fato de que toda a educação, formal ou informal, é feita de forma seletiva.

Essa condição assegura que pessoas diferentes apresentem diversas versões de um mesmo fato. Por isso, a visão humana pelas coisas materiais é sempre deformada (alterada), quando se encontra localizada em ângulos distintos: no chão, nos diversos andares de um edifício, sobrevoando de avião, e assim por diante.

Em termos gerais, o estudo da paisagem numa abordagem aplicada tem objetivos práticos na esfera do ordenamento e da gestão territorial, o que abarca a seleção de prioridades de acordo com interesses socioeconômicos e diretrizes políticas. Dessa forma, os planos devem ter em conta os atores sociais que vivem e usufruem da paisagem (agentes econômicos; forças políticas; pessoas e/ou grupos sociais, outros).

Assim posto, preliminarmente, pode se afirmar que as paisagens pelo olhar dos moradores de Igatu são diferentes ao olhar do turista. O olhar deste é direcionado para os aspectos da paisagem que o separam da experiência de todos os dias, enquanto o olhar do primeiro é influenciado por um sentimento de identidade e pertencimento local.

Ao viajar, o turista busca a mudança de ambiente, o rompimento com o cotidiano, a realização pessoal, além da concretização de expectativas, fantasias e aventuras. Esse direcionamento implica numa sensibilidade própria de cada um dos sujeitos, voltada para determinados elementos visuais, característicos de um determinado lugar visitado. Contudo, a representação da paisagem característica deste lugar encontra-se circunscrita à expectativa do turista, mas também pode ser resultado do processo de produção que nada tem de autônomo ou inteiramente subjetivo, pois o seu olhar pode ser monitorado pelos interesses do empresário do setor turístico.

Santos (1988, p. 22) propõe-se a distinguir os conceitos de paisagens em natural e artificial. Nas suas proposições de análise, ele argumenta que cada paisagem é decorrente dos diversos níveis de forças produtivas, materiais e imateriais. Pode-se, inclusive, dizer que o conhecimento é parte integrante dessas forças produtivas:

A paisagem artificial é a paisagem transformada pelo homem, enquanto grosseiramente podemos dizer que a paisagem natural é aquela ainda não mudada pelo esforço humano. Se no passado havia a paisagem natural, hoje essa modalidade de paisagem praticamente não existe mais. Se um lugar não é fisicamente tocado pela força do homem, ele, todavia, é objeto de preocupações e 
de intenções econômicas ou políticas (SANTOS, 1988, p. 64).

Santos, assegura que paisagem não é construída de uma só vez, porém é criada por processos de acréscimos e substituições. Dessa forma, justifica-se o emprego da metáfora que assegura a construção da paisagem a partir de uma escrita sobre a outra e que a paisagem é um conjunto de objetos que têm idades diferentes, enfim, uma herança de muitos e diferentes momentos.

Essas reflexões, sobre o fato de a paisagem não ser criada de uma só vez, justificam também o juízo de não permanência. Nessa perspectiva de análise, a paisagem constitui- se objeto de mudança. As formas espaciais criadas pelos homens expressam as relações sociais vigentes na época de sua realização, decorrentes da história do trabalho e das técnicas.

Dentro do processo de dominação e/ou apropriação da Vila de Igatu e do Projeto Brejo Verruga delimitados na área de estudo, o território e a territorialização são trabalhados na multiplicidade de suas manifestações históricas e socioculturais.

Nessa perspectiva, foram destacados os olhares dos diferentes agentes/atores sociais, a partir do valor de uso da paisagem local. Embora a ação humana não dependa exclusivamente da racionalidade e da escolha, há sempre uma cota de imponderabilidade na decisão.

As escolhas não intencionadas podem levar a resultados não intencionados, característica, aliás, muito comum na atividade turística. A intencionalidade dos empresários do turismo, por exemplo, que utilizam os apelos da propaganda, faz com que o turista procure cada vez mais a fantasia, o simulacro, o exotismo, a nostalgia, o novo e o diferente.

Assim, fica claro que a identidade é construída a partir de objetividades/subjetividades individuais e coletivas, e os vínculos de identificação com o lugar variam de um indivíduo para o outro, de acordo com a expectativa experiencial e comportamentos diversos. Portanto, a preferência pelas paisagens fica condicionada a intencionalidades dos agentes/atores sociais.

Nessa perspectiva, foi possível vislumbrar, por meio das entrevistas e questionários aplicados, como estas pessoas percebem o garimpo e o que a ele é afeito.

Esses atores/agentes expressam uma vivência acumulada em fases de desânimo; sentimento de orgulho pela opulência do passado e sentimento de tristeza pela decadência do presente; descrença nas instituições e formas de combate às crises cíclicas; e ao otimismo, acreditando em novas alternativas de refuncionalização do uso da gruta. Isto é assim por que a garimpagem, ontem e hoje, constitui-se num signo que representa uma região que se formou sob a sua égide.

A extração de diamantes na Chapada Diamantina promoveu concentração individual de riqueza - graças à exploração da mão de obra dos garimpeiros - e, em seguida, a desesperança e pobreza para muitos.

Contudo, o mais importante é que a comunidade regional começa a perceber que este evento veio para trazer mudanças na mentalidade, de atitudes e de trato com os recursos da natureza. O 
garimpo continua sendo um símbolo, mas não está sozinho, e sim agregando valores ao turismo ecológico, ao turismo de aventuras, ao turismo científico e histórico, que vem se desenvolvendo para dar uma nova funcionalidade ao antigo território, após o declínio da mineração.

\subsection{Método de Valoração Econômica Ambiental}

Os métodos de valoração econômica ambiental, Figura 1, são instrumentos analíticos que contribuem para uma técnica de avaliação de projetos mais abrangente: a conhecida análise custobenefício (ACB), cuja concepção teórica está baseada na Teoria Econômica Neoclássica, enfatiza a filosofia individual e a soberania do consumidor.

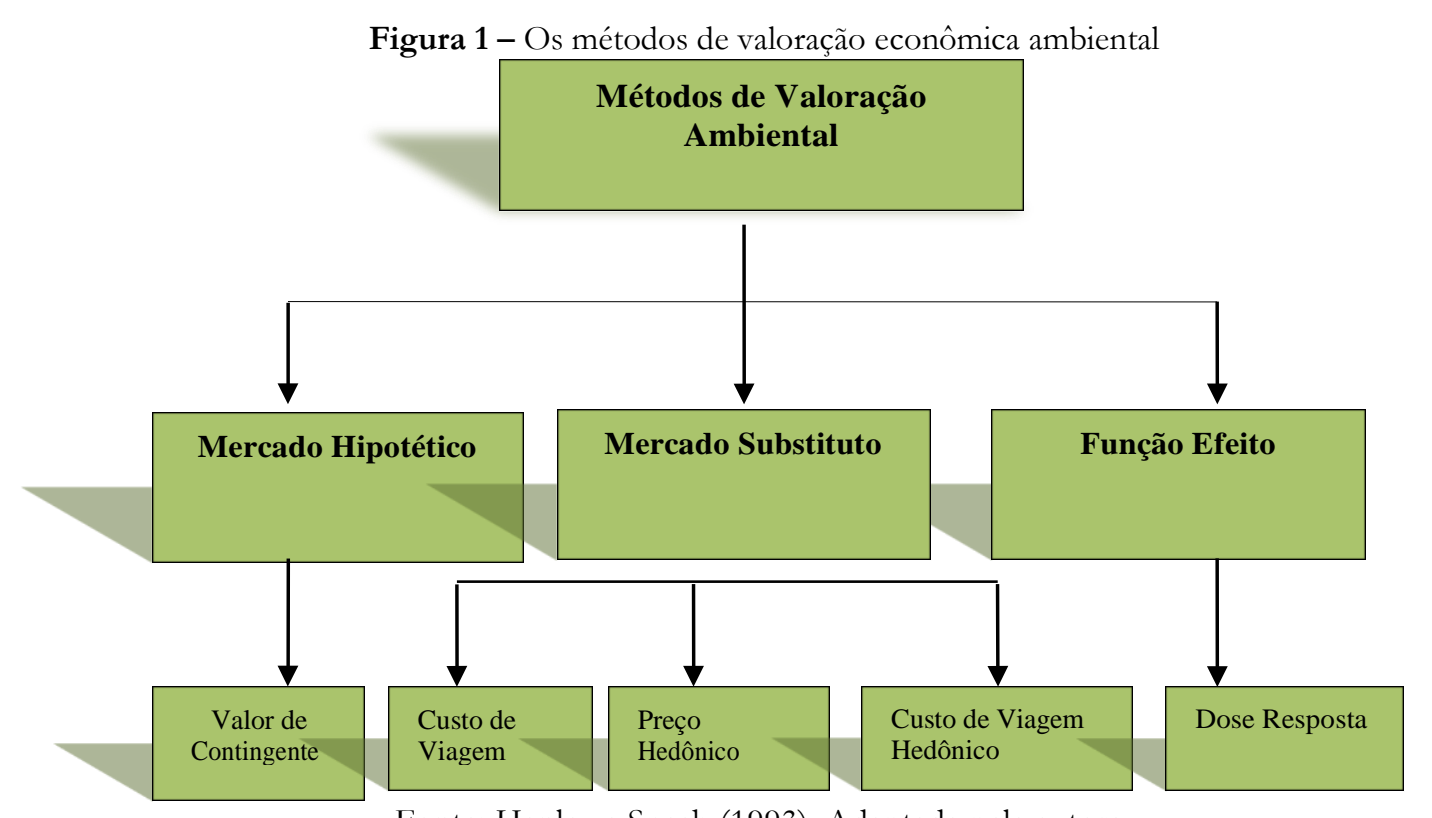

Fonte: Hanley e Spash (1993). Adaptada pela autora.

Não existe uma classificação universalmente aceita sobre as técnicas de valoração econômica ambiental, o que justifica desatacar a contribuição metodológica de alguns pesquisadores. Bateman e Turner (1992, p. 123) propõem uma classificação dos métodos de valoração econômica distinguindoos pela utilização ou não das curvas de demanda marshalliana ou hicksiana.

Nos seus estudos, Hufschmidt et al. (1983, p. 65) fazem suas divisões de acordo com o fato da técnica utilizar preços provenientes: i) de mercados reais; ii) de mercados substitutos; ou iii) mercados hipotéticos.

Nesse esforço, destacam-se as considerações dos teóricos Hanley e Spash (1993), que fazem apenas uma distinção dos métodos de valoração econômica ambiental em dois grupos:

i. $\quad$ forma direta, como o método de valoração contingente (MVC);

ii. forma indireta, como o método de preços hedônicos (MPH), o método dos custos de viagem (MCV) e as abordagens da função de produção, como o método dos custos evitados (MCE) e o método dose-resposta (MDR). 
Tomando como referência a classificação de Hanley e Spash (1993), o estudo consubstancia-se no método de valoração de bens e serviços ambientais, denominado de Método do custo viagem. Este tem como princípio básico o pressuposto de que a quantidade de visitas feitas por um turista ao ativo é uma função dos gastos, decorrente de variáveis socioeconômicas e atitudinais, de forma que uma curva de demanda seja estimada para esse mercado hipotético e o excedente do consumidor seja calculado.

Bastante específico, tal método aplica-se bem no caso de avaliação dos serviços oferecidos pelos bens naturais (parques recreativos ou locais turísticos). Esses recursos ambientais não têm preço no mercado convencional, mas as pessoas atribuem-lhes valor em decorrência do lazer, da beleza do lugar, da estética ambiental. Esta técnica se baseia no princípio de que o tempo e o dinheiro gastos na viagem para um local específico para visitar uma área ambiental indicam o valor deste bem. Uma curva de demanda é estimada através do incremento progressivo da taxa de admissão do local.

Então, o modelo assume a forma funcional $V_{i}=f\left(P_{i}, R_{i}, K_{i}\right)$, em que: $V_{i}=$ densidade de viagem por zona; $\mathrm{P}_{\mathrm{i}}=$ preço de viagem (no qual se computam os gastos com combustível, alimentação, bilhete de acesso ao local, aquisição de souvenir, custo de oportunidade do tempo e outros custos extras); Ri = renda média dos visitantes; e Ki= variáveis que refletem as atitudes dos turistas em relação ao local de visita. A partir da estimativa, é possível determinar, em termos monetários, o excedente dos usuários, ou seja, o valor dos benefícios monetários auferidos pelos frequentadores do local de recreação, conforme Figura 2.

Figura 2 - Taxa de Visitas

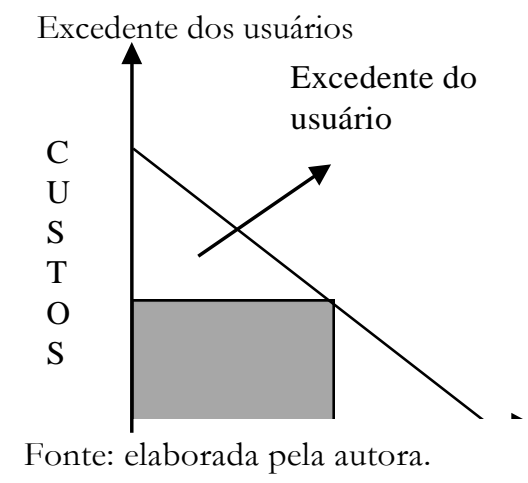

O uso do Método do Custo de Viagem é adequado na avaliação de parques e outros atrativos turísticos. Ele possui uma facilidade adicional, do ponto de vista operacional, pois requer amostragens de frequentadores obtidas no próprio sítio, evitando, assim, a pesquisa de rua ou de amostra domiciliar, o que invariavelmente requereria um número muito maior de entrevistados. 


\subsection{A Valoração da Paisagem Centrada no Sujeito}

Nesse artigo, optou-se em aplicar o método de valoração econômica, mediante abordagem centrada no sujeito. Para a fundamentação quantitativa e qualitativa proposta na análise de custobenefício dos projetos ambientais, buscam-se os elementos na Teoria da Percepção Ambiental, no que se refere à valoração do meio ambiente, no município de Andaraí, Bahia, dando ênfase:

- À beleza cênica associada ao estado de conservação e alterações ambientais, na situação em que não exista mercado para os referidos bens, a exemplo, de espécies em extinção ou raras, santuários ecológicos ou algum ecossistema raro ou único;

- À questão espacial, enfatizando a valorização das relações carregadas de emoção dos indivíduos e grupos sociais com os lugares e regiões. Enfatiza-se, assim, a topofilia, ou seja, o elo efetivo entre a pessoa e o lugar. A perspectiva da análise da percepção é como consequência, bastante valorizada (TUAN, 1983);

- Ao comportamento dos diversos agentes sociais locais, no tocante ao grau de afetividade e significado relativo, que os levam a agir e a reagir sobre o meio circundante, influenciado em parte pelo modo de elaborar e refletir sobre os resultados de suas experiências com o mundo, ou melhor, com seu espaço;

- Ao sentimento dos turistas "transitórios e pessoais" (TUAN, 1983) incentivados sob infinitas formas em relação à área de estudo, em confronto com o elo efetivo dos moradores e lugares, que intrinsecamente confundem-se com a própria história de vida, carregados de emoção.

\section{ASPECTOS METODOLÓGICOS DA PESQUISA}

Nessa pesquisa, o tamanho da amostra foi estimado em 300 visitantes aos atrativos turísticos. Baseou-se na metodologia proposta por Barbetta (2006), considerando 95\% de confiabilidade e 5\% de erro amostral (Eo) nas estimativas estatísticas.

A aplicação da técnica intitulada MCV deveu-se ao fato de sua metodologia basear-se na criação de um mercado hipotético de produtos e serviços ambientais, para captar a disposição de pagar dos indivíduos.

$\mathrm{Na}$ pesquisa de campo foram aplicados questionários, logo à entrada Vila de Igatu, entorno, e Projeto Brejo Verruga, contendo questões que procuravam capturar o perfil do visitante e informações necessárias à aplicação do Método do Custo de Viagem.

O questionário foi dividido em partes, conforme os objetivos de pesquisa, definindo: Perfil dos frequentadores desses atrativos turísticos; O levantamento dos gastos de viagem e dos gastos no entorno da Vila de Igatu e do Projeto Brejo Verruga; Dados sobre a composição do grupo; Perguntas específicas de forma a evidenciar o problema decorrente das viagens com múltiplos propósitos e 
destinos dos visitantes; A disposição a pagar pelos atrativos turísticos.

Com base na amostragem do universo entrevistado, no local de pesquisa, quase não houve frequentadores que percebessem renda familiar abaixo de $\mathrm{R} \$ 3.500,00$. Ao contrário, a renda modal teve frequência alta, conferindo forte uniformidade entre os visitantes (quase todos com renda familiar média entre $\mathrm{R} \$ 3.500,00$ e $\mathrm{R} \$ 4.500,00)$.

\section{RESULTADOS DO MÉTODO CUSTO VIAGEM: VILA DE IGATU E DO PROJETO BREJO VERRUGA}

Nesta seção, são apresentadas algumas características dos entrevistados e também os resultados estatísticos do Método do Custo de Viagem, definido na amostra de pesquisa.

\section{1 Perfil modal do frequentador}

No trabalho empírico, observou-se uma presença de visitantes, cujo percentual de $45 \%$ era do sexo masculino e 55\%, do sexo feminino. No que se refere à faixa etária, o turismo na Chapada Diamantina tem a preferência do público jovem, dado que $54 \%$ do total perguntado situaram-se entre 18 e 35 anos.

Portanto, exceto quanto ao gênero e à região onde mora, há uma uniformidade grande do perfil do visitante, sobretudo no que se refere à renda familiar e ao nível educacional ( $80 \%$ dos entrevistados com mais de 25 anos tinham nível superior completo ou estavam na faculdade).

A Tabela 1 relaciona algumas estatísticas básicas com referência às características dos 300 entrevistados, de acordo com a amostra definida, necessária à valoração monetária do patrimônio histórico cultural da área de pesquisa.

Tabela 1 - Frequentadores do Patrimônio Histórico Cultural da Vila de Igatu e do Projeto Brejo Verruga

\begin{tabular}{l|l|c|c|c}
\hline \multicolumn{1}{c|}{ Variáveis } & $\begin{array}{c}\text { N } \\
\text { (incluídas) }\end{array}$ & Média & Variância & Desvio-padrão \\
\hline Renda Pessoal (RP) & 300 & 3.998 & 230.470 & 480,07 \\
\hline Renda Familiar (RF) & 300 & 4.245 & 46.560 & 216 \\
\hline Duração Viagem (DV) & 300 & 2,15 & 0,47 & 0,68 \\
\hline Duração na Vila e Projeto (VP) & 300 & 1,19 & 0,24 & 0,49 \\
\hline Gastos de Viagem (GV) & 300 & 1.199 & 20.742 & 144 \\
\hline Gastos no Entorno (GE) & 300 & 79,95 & 92 & 9,6 \\
\hline Nr. acompanhantes (NA) & 300 & 2 & 0,94 & 0,97 \\
\hline Disposição-a-pagar (WTP) & 300 & 119,93 & 207 & 14,4 \\
\hline
\end{tabular}

Fonte: valores obtidos a partir dos dados da pesquisa de campo. 


\subsection{Renda pessoal e renda familiar}

A renda pessoal e renda familiar resultaram em valores médios de $\mathrm{R} \$ 3.997,50$ e de $\mathrm{R} \$ 4.244,67$, respectivamente. No caso dos visitantes ao Patrimônio Histórico Cultural da Vila de Igatu e do Projeto Brejo Verruga, a quase totalidade provém da classe média, em torno de $0,67 \% ; 29,67 \% ; 33 \% ; 36,67 \%$ dos frequentadores são de famílias com renda em torno de 3.500,00; $\mathrm{R} \$ 4.000,00 ; \mathrm{R} \$ 4.200,00$ e $\mathrm{R} \$$ 4.500,00, respectivamente.

O modelo de questionário aplicado concentrou-se nas famílias com renda igual ou inferior a $\mathrm{R} \$$ 4.500,00 (ponto médio do intervalo da amostra: $R \$ 4.200,00$ a $R \$ 4.500,00$ ), que envolve a grande maioria dos frequentadores dos pontos turísticos.

$\mathrm{Na}$ Tabela 1, é possível ser observado que os desvios-padrão são relativamente baixos com relação aos valores das médias. Cabe observar que os resultados encontrados sinalizam uma amostra da pesquisa com pouca variância/dispersão nos dados ao redor da média.

Com base na amostragem do universo entrevistado de turistas que visitam a Região da Chapada Diamantina, a atividade turística tem como característica a regionalidade, haja vista que $56 \%$ do total do fluxo turístico são provenientes do estado da Bahia. A seguir, brasileiros de outros estados contribuem com $26 \%$ do fluxo turístico total receptivo, sendo em terceiro lugar os estrangeiros, com um percentual de $18 \%$.

Observou-se que o motivo da viagem continua sendo lazer, cujo principal meio de transporte à região é feito basicamente de ônibus e carro, restringindo-se o uso do transporte aéreo a um limitado número de turistas.

É possível verificar diretamente nos microdados o inexpressivo turismo de excursão, predominando o turismo em família ou com amigos. $O$ frequentador-padrão desse patrimônio histórico cultural da Vila de Igatu e do Projeto Brejo Verruga é tipicamente o jovem da classe média, universitário ou formado, que visita o local pela primeira vez em companhia de amigos.

\subsection{Objetivos da visita}

No conjunto do fluxo de turistas nacionais e estrangeiros, $97 \%$ dos entrevistados responderam que o parque é o principal motivo da viagem, representado pelos seus atrativos naturais (trilhas, cachoeiras, vegetação, grutas e rios), para visitar a Região da Chapada Diamantina. Dentre as atividades que os turistas mais gostam de exercer ao ar livre, destacou-se em 97\% a caminhada, e em seguida o montanhismo. 


\subsection{Lógica do excedente do consumidor}

Os números de visitantes da tabela abaixo por região de origem e dados de frequência foram obtidos pelo IBAMA/base local para 2016. Esses dados são apresentados na Tabela 2, que apontam as populações das Regiões 1 e 2 com renda familiar maior do que R $\$ 3.000,00$, com idade superior a 15 anos e inferior a 50 .

Tabela 2 - Populações que visitam o Patrimônio Histórico Cultural da Vila de Igatu e do Projeto Brejo Verruga (\%)

\begin{tabular}{l|l|c|c|l}
\hline Local & $\begin{array}{l}\text { População de 15 a } \\
\text { 49 anos }\end{array}$ & Total de visitas & \% da população & $\begin{array}{l}\text { Custo Total de } \\
\text { Viagem }\end{array}$ \\
Bahia & 250.000 & 785 & $0,31 \%$ & $0,05 \%$ \\
Outros Estados & 500.000 & 262 & & $\mathbb{R} \$ 1.279,20$ \\
& & & & \\
\hline
\end{tabular}

Fonte: Dados adaptados, valores obtidos a partir do IBAMA (2016).

O cálculo do excedente do consumidor ${ }^{2}$ é muito útil para a análise da implementação de uma política pública ambiental. Dessa forma, o benefício total líquido obtido pelos frequentadores que visitam o Patrimônio Histórico Cultural da Vila de Igatu e do Projeto Brejo Verruga foi obtido da seguinte forma:

Do total dos entrevistados oriundos da Bahia e outros Estados, praticamente ninguém estaria disposto a pagar mais do que $\mathrm{R} \$ 1.439,16$ anualmente. Em torno de 0,31\% desses estariam dispostos a pagar até $\mathrm{R} \$ 1.439,16$; e $0,05 \%$ estariam dispostos a pagar até $\mathrm{R} \$ 1.250,00$ para preservar/conservar o meio ambiente.

Dessa forma, temos:

$$
\mathrm{CS}=\mathrm{CS}_{1}+\mathrm{CS}_{2} \text {, sendo que: }
$$

$\mathrm{CS}_{1}=\{(1.439-1.250) \times(0,31 \times 250.000) / 2\}=\mathrm{R} \$ 7.323 .750$ e $\mathrm{CS}_{2}=\{(1.439-1.250) \times(0,05 \mathrm{X} 500.000) / 2\}=\mathrm{R} \$$ 2.362.500.

Então, o somatório destes montantes indica o valor total do excedente do consumidor, que representa o valor do benefício líquido total de $\mathbf{R} \mathbf{9} \mathbf{9 . 6 8 6 . 2 5 0}$ (benefícios para os compradores do mercado menos o montante pago pelos compradores), decorrente da visitação de 102.500 turistas (uso direto) dos atrativos turísticos.

Para obtermos o valor total do Patrimônio Histórico Cultural, acrescentaram-se:

- Os custos totais dos visitantes $=1.439$ X 785 pop.visitante entre 15 e 49 anos +1.250 x 262 pop.visitante entre 15 e 49 anos $=\mathbf{R} \$ \mathbf{1 . 4 5 7 . 1 1 5 , 0 0 . ~}$

\footnotetext{
2 Marshall define como a quantia excedente e acima do preço real pago pelo consumidor que prefere obter um
} quantum de um bem do que não obtê-lo. 
Assim, os custos totais são de $\mathbf{R} \mathbf{R} \mathbf{R} \mathbf{1 . 4 5 7 . 1 1 5 , 0 0}$. Acrescidos ao valor do excedente do consumidor, na ordem de $\mathbf{R} \mathbf{9} \mathbf{9 . 6 8 6 . 2 5 0}$, resulta-se no valor total do Patrimônio Histórico Cultural da Vila de Igatu e do Projeto Brejo Verruga em R\$ 11.143.365,00.

\section{CONSIDERAÇÕS FINAIS}

O estudo de valoração econômica do patrimônio histórico cultural da Vila de Igatu e do Projeto Brejo Verruga revelou-se uma experiência de pesquisa válida, permitindo alcançar os objetivos para estimar o valor da paisagem ambiental, a partir da fundamentação teórico-metodológica adotada.

Do ponto de vista metodológico e operacional, os métodos disponíveis que fundamentam a valoração econômica do meio ambiente demonstram ser úteis, mas ainda sujeitos a algumas limitações. Acredita-se, porém, que os trabalhos de pesquisa que estão sendo realizados no Brasil trarão significativos avanços nos próximos anos.

Assim sendo, legitima-se parcialmente com o pressuposto da hipótese, quando se afirma que a técnica do Método Custos de Viagem (MCV) constitui-se num método de avaliação monetária, capaz de valorar o uso a locais abertos à visitação pública em geral, a exemplo de locais turísticos.

A partir da pesquisa bibliográfica deste estudo, conclui-se que a responsabilidade individual frente a externalidades não está solucionada pela falta de definição dos direitos de propriedade e a possibilidade de aproveitamento coletivo advindo da conservação/preservação ambiental. Por sua vez, existe a dificuldade em induzir os indivíduos a revelarem sua verdadeira disposição de pagar pela conservação/preservação do recurso ambiental.

Os estudos que envolvem os métodos de valoração ambiental a partir da valoração da paisagem se tornam cada vez mais importante, pois podem fornecer informações que demonstrem ou não a necessidade de conservar/preservar determinadas áreas ambientais; apresentar soluções práticas aos problemas de ocupação de territórios e planejamento para ocupação de áreas que causem menos impacto ao ambiente natural.

Por outro lado, observa-se que o valor dos atrativos turísticos pontuados pelos turistas está condicionado a um programa gerenciado pelas agências do turismo, que sutilmente direcionam a escolha do turista, controlam e determinam lugares que devem ou não ser vistos, pois, longe de se criar uma identidade, produzem-se mercadorias para serem consumidas segundo os interesses empresariais.

Inicialmente, a escolha do produto turístico local pelo visitante é decorrente do acesso aos postais, das sugestões das agências de viagens, das revistas de viagens, do acesso à internet e da televisão.

$\mathrm{Na}$ pesquisa empírica, percebe-se nitidamente a tendência dos moradores da Vila de Igatu a valorizarem os atrativos turísticos, associando-os ao valor intrínseco expresso ao elo afetivo com a região, que se confunde com a própria história pessoal de vida carregada de emoções. 
$\mathrm{Na}$ dualidade e expectativa de funcionalidade/refuncionalidade da gruta, vivenciada pelos moradores locais, é possível explicar a identidade individual e social dos moradores de Igatu, local onde se encontra instalado o Projeto Brejo e Verruga. Ambas as identidades são dotadas de objetividade e subjetividade, mobilizadas por um poder simbólico.

O sentimento de identidade desses moradores locais é fortemente influenciado pelo sentimento de sua pertença ao garimpo nos moldes tradicionais, atrelado aos seus mecanismos de afiliação/ exclusão. A identidade cultural dos ex-garimpeiros move os sentimentos, os valores, e apresenta o reflexo da convivência humana. Nesse propósito, a identidade social pode ser entendida como identidade territorial, no momento em que o referencial simbólico central para a construção da identidade passa ou mesmo transpassa o território.

Em específico, a extração de diamantes se constitui em referência para a construção da identidade local e passa a ser concebida como uma espécie de condensamento da memória coletiva. Assim, a construção do imaginário de identidade envolve uma escolha na refuncionalização do espaço, por meio do Projeto Brejo e Verruga, lugar do passado, utilizado pelo garimpo, porém capaz de fazer sentido na atualidade vivenciada pelos moradores de Igatu.

\section{Referências}

BARBETTA, Pedro A. Estatística aplicada às Ciências Sociais. 6. ed. Florianópolis: Editora da UFSC, 2006.

BATEMAN, Lan; TURNER, Kerry. Valuation of the Envinment, Methods and Techniques: The Contingent Valuation Method. In:________ (Ed.). Sustainable Environmental Economics and Management. London and New York: Belhaven, 1992.

HANLEY, Nick; SPASH, Clive L. Cost-Benefit Analysis and the Environment. Hants, Inglaterra: Edward Elgar, 1993.

HUFSCHMIDT, Maynard M. et al. Environment, Natural Systems, and Development: An Economic Valuation Guide. Baltimore, EUA: Johns Hopkins University Press, 1983.

SANTOS, Milton. Metamorfoses do espaço habitado. São Paulo: Hucitec, 1988.

TUAN, Y. F. Space and Place: the Perspectives of Experience. Minneapolis: Univ. of Minnesota Press; London: Edward Arnold's, 1977. Paperback edition, University of Minnesota Press, 1979. Portuguese transl., Sao Paulo: Difel, 1983.

1983.

. Espaço e lugar. A perspectiva da experiência. Tradução de Lívia de Oliveira. São Paulo: DIFEL, 